\title{
Low Temperature Combustion of Jet Propellant-8 Fuel in Compression Ignition Engine with the Low Compression Ratio
}

\author{
Grzegorz Pawlak ${ }^{1 *}$, Patryk Płochocki', Tomasz Skrzek² \\ 1 Military Institute of Automotive and Armor Technology, Okuniewska 1, 05-070 Sulejówek \\ 2 Faculty of Mechanical Engineering, Kazimierz Pulaski University of Technology and Humanities in Radom, ul. \\ Chrobrego 45, 26-200 Radom \\ *Corresponding author's e-mail: grzegorz.pawlak@witpis.eu
}

\begin{abstract}
Jet Propellant-8 (JP-8) is used as a fuel for a standard Compression Ignition (CI) engine instead of diesel oil, especially in the military applications. The properties of a kerosene-type fuel, which is JP-8, encourage us to test different strategies of mixture creation and combustion, which could be more effective for this fuel than these elaborated for diesel oil. The experiment aimed to show whether it is possible to realise an effective Low Temperature Combustion (LTC) strategy in a CI engine with a low compression ratio for JP-8 fuel. The tests were focused on the combustion of a lean homogeneous JP-8/air mixture close to the knock limit. Additionally, the combustion process of the homogeneous mixtures diluted with EGR was examined. The AVL research engine with a common rail system and low compression ratio $(\mathrm{CR}=12)$ was adapted for the tests. In order to create a homogeneous mixture early, multi injection of JP-8 under high pressure $(90 \mathrm{MPa})$ was applied. The results of the HCCI operation were compared to the Partially Premixed Combustion (PPC) mode without EGR, tested on the same engine with a low CR. The experiment showed that it is possible to realise the LTC process for the HCCI engine fueled with JP-8, though the knock limited the engine load. The application of EGR allowed controlling the phase and rate of the heat release. The higher share of EGR made the HCCI engine cycles less repetitive. Generally, for the HCCI engine operation, the $\mathrm{CO}$ and total hydrocarbons (THC) emissions were on a high level. The PM emission was also relatively high, whereas $\mathrm{NO}_{\mathrm{x}}$ was maintained on a low level for all of the examined points.
\end{abstract}

Keywords: Low Temperature Combustion, HCCI engine, Partially Premixed Combustion, Jet Propellant-8.

\section{INTRODUCTION}

Jet Propellant 8 (JP-8) is a military kerosenetype aviation turbine fuel with Fuel System Icing Inhibitor (FSII). FSII allows the fuel molecule to be soluble in both nonpolar fuels as well as in polar water. The fuel properties allow it to be used as a unified NATO fuel (NATO code F-34) [15], so it is also employed as a fuel for internal combustion engines, especially for heavy duty CI engines [11]. The HCCI combustion is considered to be a clean and efficient combustion technology. It offers a wide range of fuel flexibility [14] with higher thermal efficiency and low emissions. Low Temperature Combustion (LTC) realised with the use of HCCI technologies suppresses the $\mathrm{NO}_{\mathrm{x}}$ and soot emissions from the engine, but the operating range is influenced by the auto-ignition properties of the fuel, engine geometry and is confined by the engine knock and a high Unburnt Hydrocarbons (UHC) and $\mathrm{CO}$ emissions $[4,13]$. In the implementation of the HCCI process, the engine compression ratio is a crucial design parameter. The engine knock depends on the in-cylinder conditions, where the temperature is crucial. The low compression ratio minimises temperature during the compression stroke.

The experiment presented in the paper was focused on the possible realisation of the HCCI process with the application of the JP-8 fuel for a CI engine with low CR with or without EGR. EGR had both thermal and chemical effects on the HCCI combustion [18]. If the temperature of the gases is lower or of the same order as the 
intake gas temperature, then the effect of the EGR might have been reduced to only dilution effects [2]. In the experiment, EGR was used only for dilution of the air-fuel mixture. The results of the HCCI operation were compared to the Partially Premixed Combustion (PPC) mode without EGR, tested on the same engine with a low CR.

\section{JP-8 AS A FUEL FOR LTC PROCESS}

The JP-8 fuel properties give possibilities to experiment with different types of combustion strategies. This kerosene-type aviation turbine fuel is a reactive fuel $(\mathrm{CN}=45)$. Typical JP-8 distillation curves start from $438 \mathrm{~K}$ and finish at $570 \mathrm{~K}$, but a typical aromatics level is $17.3 \%$ by volume [5] (normal diesel oil contains 4\%-5\% vol. of aromatics) (Table 1). This is a reason for the reduction in the cetane number of fuel with increased aromatic content. The JP-8 properties are described in Table 1. Typically, the LTC strategies rely on long ignition delays to increase fuel-air mixing, reducing local equivalence ratios or temperature or both. The charge dilution (with either air or EGR) is used to lower combustion temperature in the cylinder, and as a result, $\mathrm{NO}_{\mathrm{x}}$ formation is limited. The LTC strategies are categorised into homogeneous charge compression ignition (HCCI) and Partially Stratified Charge Compression Ignition (SCCI). The HCCI strategy relies on the auto-ignition of a fully premixed air-fuel charge which creates a lean mixture [13]. Mixture auto-ignition properties, heat rate release and, as a result, temperature and pressure history in the cylinder are affected by

Table 1. JP-8 fuel vs. diesel oil properties [9]

\begin{tabular}{|c|c|c|}
\hline Property & JP-8 & Diesel oil \\
\hline Approximate formula & $\mathrm{C}_{11} \mathrm{H}_{21}$ & $\mathrm{C}_{12} \mathrm{H}_{23}$ \\
\hline Cetane number & 45 & 50 \\
\hline Liquid density at $15^{\circ} \mathrm{C}\left(\mathrm{kg} / \mathrm{m}^{3}\right)$ & 804 & 831 \\
\hline Low heating value $(\mathrm{MJ} / \mathrm{kg})$ & 42.8 & 43.2 \\
\hline Kinematic viscos- & 1.27 & 2.35 \\
\hline ity at 313K $\left(\mathrm{mm}^{2} / \mathrm{s}\right)$ & 3000 & 350 \\
\hline Sulfur kontent $(\mathrm{mg} / \mathrm{kg})$ & 57 & 66 \\
\hline Flash point $\left({ }^{\circ} \mathrm{C}\right)$ & -54 & -31 \\
\hline Cold filter plugging point $\left({ }^{\circ} \mathrm{C}\right)$ & & \\
\hline Distillation $\left({ }^{\circ} \mathrm{C}\right)$ & 167 & 178 \\
- - start & 202 & 255 \\
$-50 \%$ & 238 & 353 \\
\hline
\end{tabular}

many factors, but the type of fuel is one of the most crucial. The auto-ignition characteristics of a fuel in the HCCI engine operation are categorised into single-stage ignition and two-stage ignition process. Two-stage ignition fuel has a separate region with a small heat release in the low temperature regime around $10-20 \mathrm{CAD}$, before the main heat release in the high temperature regime. In this case, Low Temperature Heat Release (LTHR) or "cool-flame" oxidation reactions take place at the start of the ignition when the temperature is in the range of $760-880 \mathrm{~K}$ before attaining the Intermediate Temperature Heat Release (ITHR) phase [20]. Lower octane fuels (less auto-ignition resistant) such as diesel, n-heptane, PRF80 (80\% iso-octane and 20\% nheptane) and DME exhibit a two-stage ignition [13]. JP-8 belongs to this group. The HCCI engine operation by two-stage ignition fuels needs lower charge preheating or lower compression ratios because LTHR raises the charge temperature in the cylinder [19]. A reduction of CR decreases the charge temperature during the compression stroke of the engine, and the ignition delay could be prolonged [11]. Because the combustion of homogeneous or nearly homogeneous mixtures involves simultaneous heat release in a spatially vast region, so-called diesel knock appears and limits the maximum load. For the HCCI engine operation, $0.5 \mathrm{MPa}$ of Indicated Mean Effective Pressure (IMEP) is reported as the maximum achieved in a naturally aspirated HCCI engine using a well-mixed fuel-air mixture [13]. In [16], the effect of reducing $C R$ on the HCCI combustion was analysed. The paper reported that reduction of CR from 18:1 to 12:1 reduced the knocking of the engine and allowed to increase maximum IMEP from $0.27 \mathrm{MPa}$ to $0.35 \mathrm{MPa}$. Many researchers confirm that:

1. the liquid-phase penetration of JP-8 is lower than that of diesel oil $[3,17,8]$,

2 . the oxidation process of JP-8 is faster than diesel oil [7],

3. the JP-8 vaporisation characteristics are superior to diesel oil [1].

These are the reasons that JP-8 could not easily tolerate higher CRs. Moreover, the injector nozzle from the injection unit of the engine fuelled with diesel oil usually is not optimal for JP-8 fuel, especially for HCCI fuelling. A narrow fuel spray angle and a dual injection described in [10], show positive results of injector adaptation. 
Table 2. Engine characteristics

\begin{tabular}{|c|c|}
\hline Model & AVL 5402 \\
\hline Type & $\begin{array}{c}\text { naturally aspirated } \\
\text { direct injection (common rail) }\end{array}$ \\
\hline Number of cylinders & 1 \\
\hline Displacement $\left[\mathrm{cm}^{3}\right]$ & 511 \\
\hline Bore / stroke $[\mathrm{mm}]$ & $85.01 / 90.00$ \\
\hline Cycle & four stroke \\
\hline Compression ratio & $12: 1$ \\
\hline Maximum power $[\mathrm{kW}]$ & ca.16 \\
\hline Maximum speed [rpm] & 4200 \\
\hline Inlet valve: & 346.0 CA \\
open \\
close
\end{tabular}

For Partially Premixed Combustion (PPC), fuel is directly injected to the combustion chamber, and a stratified premixed charge is burned. The PPC heat release process includes four phases:
- ignition delay,

- low-temperature reaction,

- premixed combustion phase,

- late mixing controlled phase.

In the premixed combustion phase, local areas of high temperature are created and despite relatively low ambient cylinder temperature $\mathrm{NO}_{x}$ emission is higher than for $\mathrm{HCCI}$ combustion. The PPC was tested in the experiment to compare the results with the HCCI engine operation.

\section{EXPERIMENT}

The experiment aimed to test of possibilities of Low Temperature Combustion (LTC) in a CI engine fueled with JP-8 with a low compression ratio (CR). The tests were carried out on a naturally aspirated AVL experimental common rail, CI engine (Table 2). The compression ratio was set to $12: 1$. The engine parameters are given in Tab. 2. A schematic diagram of the test setup used in this study is shown in Fig. 1.

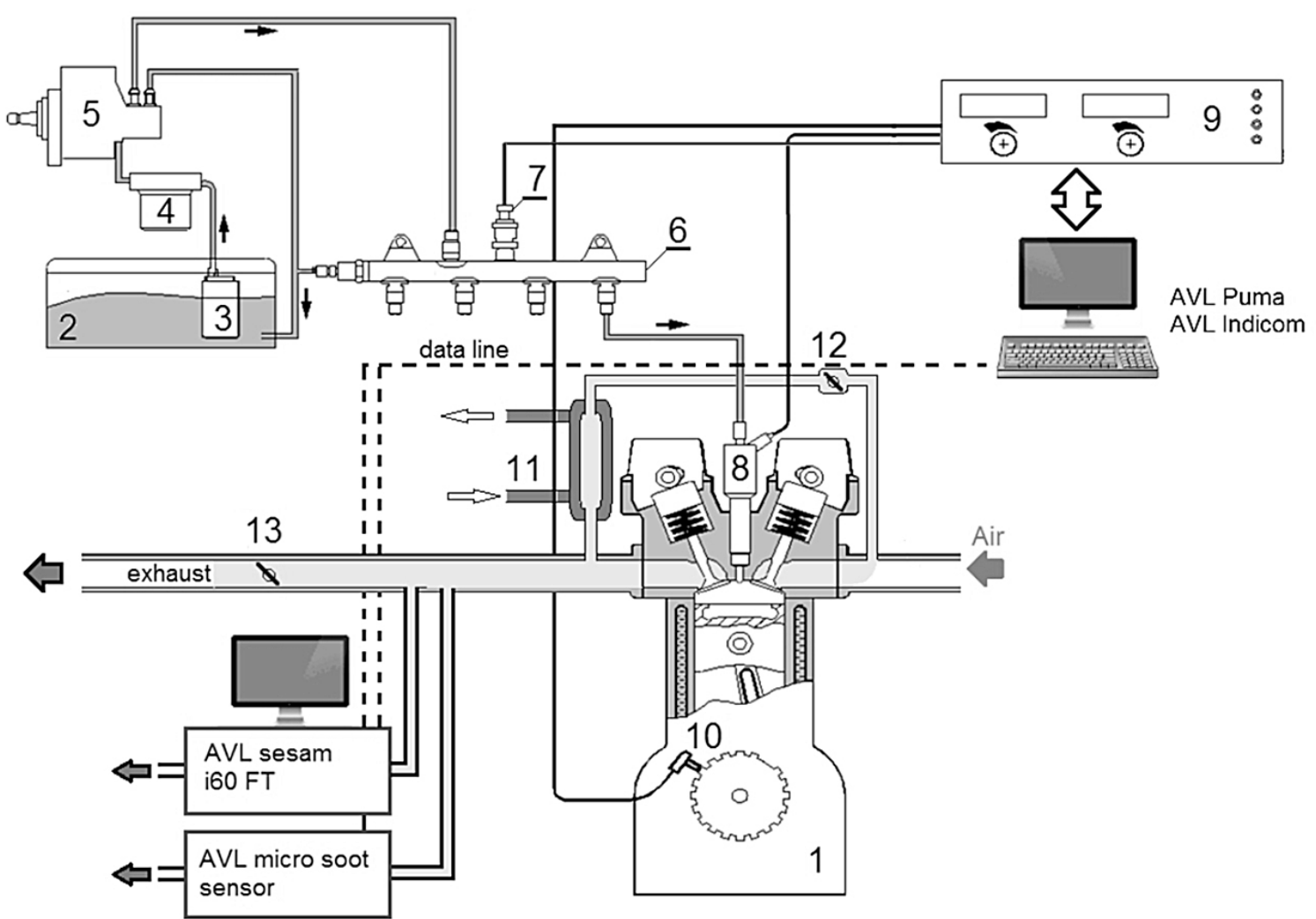

Fig. 1. Test setup. 1) AVL 5402 engine, 2) fuel tank, 3) electric fuel pump, 4) fuel filter, 5) highpressure fuel pump, 6) rail, 7) fuel pressure sensor, 8) injector, 9) controller of common rail supply system, 10) crank shaft speed sensor, 11) EGR cooler, 12) EGR valve, 13) exhaust throttle 


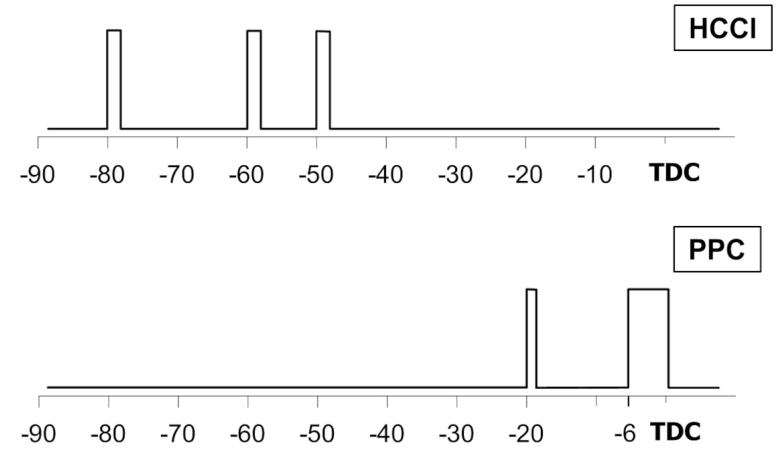

Fig. 2. Fuel injection strategies for HCCI and PPC

The initial tests of the engine preceded the proper experiment. They gave some information about the fuel injection parameters. The initial tests allowed us to choose the fuel dose per cycle and to set its division as well as to regulate the injection timing. The limit of the rate of pressure rise was set at $d p / d \varphi_{\max }=0.8 \mathrm{MPa} / \mathrm{deg}$ to avoid an excessive diesel knock, although some points with a higher rate of pressure rise were also examined.

The engine operation was analysed for two JP-8 fuel doses. The first fuel dose per cycle was set at a level which allowed the realisation of a homogeneous charge combustion without EGR with the maximum possible engine load. It was $d_{1}=14.6 \mathrm{mg} / \mathrm{cycle}$. In order to ensure the maximum mixture homogeneity, a high injection pressure $p_{\text {in }}=90 \mathrm{MPa}$ was applied. After some tests, which also involved $\mathrm{CO}$ and total hydrocarbon emissions analysis (engine emissions during the preliminary tests were minimised), the dose of the fuel injected per one cycle was divided into three equal injections per cycle $(3 \times 4.88 \mathrm{mg} / \mathrm{cycle})$. The injections were set at: $80 \mathrm{deg} / 60 \mathrm{deg} / 50 \mathrm{deg}$ BTDC and were fixed for all examined points for the HCCI engine operation (Fig. 2). In order to test the possibility of controlling the combustion process of the homogeneous mixture, EGR was applied. The EGR rates for the tests with the first fuel dose $\left(d_{1}=14.6 \mathrm{mg} /\right.$ cycle $)$ were set to $15 \%$, $30 \%$. In order to establish the same preliminary temperature condition for all tested points, the inlet temperature was maintained on the same level $(313 \mathrm{~K})$. The HCCI engine operation without EGR was compared to the PPC strategy for the same, low compression ratio. In this case, the same fuel dose $\left(d_{1}=14.6 \mathrm{mg} /\right.$ cycle $)$ was divided into the pilot dose $\left(d_{p}=2.25 \mathrm{mg}\right)$ and the main dose $\left(d_{m}=12.35 \mathrm{mg}\right)$. Taking into account the rate of the cylinder pressure rise limit, as well as minimising the $\mathrm{CO}$ and total hydrocarbon (THC) emissions the injection timing was set to $20 \mathrm{deg}$ BTDC for the pilot dose and 6 deg BTDC for the main dose. For this case, the injection pressure was reduced by half to $45 \mathrm{MPa}$. For the higher injection pressure, the engine simply did not run. The injected and evaporated fuel absorbed too much heat in a short time, and the self-ignition for a higher injection pressure was impossible. It looked like $\mathrm{CR}=12$ :1 was too low for this strategy, so PPC was realised only without dilution of the mixture.

The second tested dose of JP-8 fuel was set to $d_{2}=17.5 \mathrm{mg} /$ cycle. It gave the possibility to increase the engine load and to test a homogeneous charge combustion with the rising knock. Moreover, some points with a greater EGR rate in a homogeneous JP-8/air mixture were tested. The EGR rates for the second fuel dose $\left(d_{1}=17.5\right.$ $\mathrm{mg} /$ cycle) were set to $20 \%, 30 \%$ and $40 \%$. The engine run for this dose was not possible for the share of EGR lower than 20\%. The results obtained for the HCCI engine operation for a greater fuel dose were compared to PPC mode without $\mathrm{EGR}$, as it was done in the case of the smaller dose $\left(d_{1}\right)$. In order to have a better understanding

Table 3. Experiment conditions

\begin{tabular}{|c|c|c|c|c|}
\hline Specification & \multicolumn{2}{|c|}{$\mathrm{HCCl}$} & \multicolumn{2}{|c|}{ PPC } \\
\hline Fuel dose (mg/cycle) & 14.6 & 17.5 & 14.6 & 17.5 \\
\hline Dose division & $3 \times 4.88$ & $3 \times 5.82$ & $\begin{array}{c}2.25 \text { (pilot dose) } \\
12.35 \text { (main dose) }\end{array}$ & $\begin{array}{c}2.25 \text { (pilot dose) } \\
15.25 \text { (main dose) }\end{array}$ \\
\hline $\begin{array}{l}\text { Injection timing } \\
\text { (deg BTDC) }\end{array}$ & \multicolumn{2}{|c|}{$80 / 60$ / 50} & \multicolumn{2}{|c|}{$\begin{array}{l}20 \text { (pilot dose) } \\
6 \text { (main dose) }\end{array}$} \\
\hline EGR shares (\%) & $\begin{array}{c}0 \\
15 \\
30\end{array}$ & $\begin{array}{l}20 \\
30 \\
35\end{array}$ & \multicolumn{2}{|c|}{0} \\
\hline Inlet air or air/EGR mixture temperature $\left({ }^{\circ} \mathrm{C}\right)$ & \multicolumn{4}{|c|}{40} \\
\hline Engine speed (rpm) & \multicolumn{4}{|c|}{1200} \\
\hline
\end{tabular}



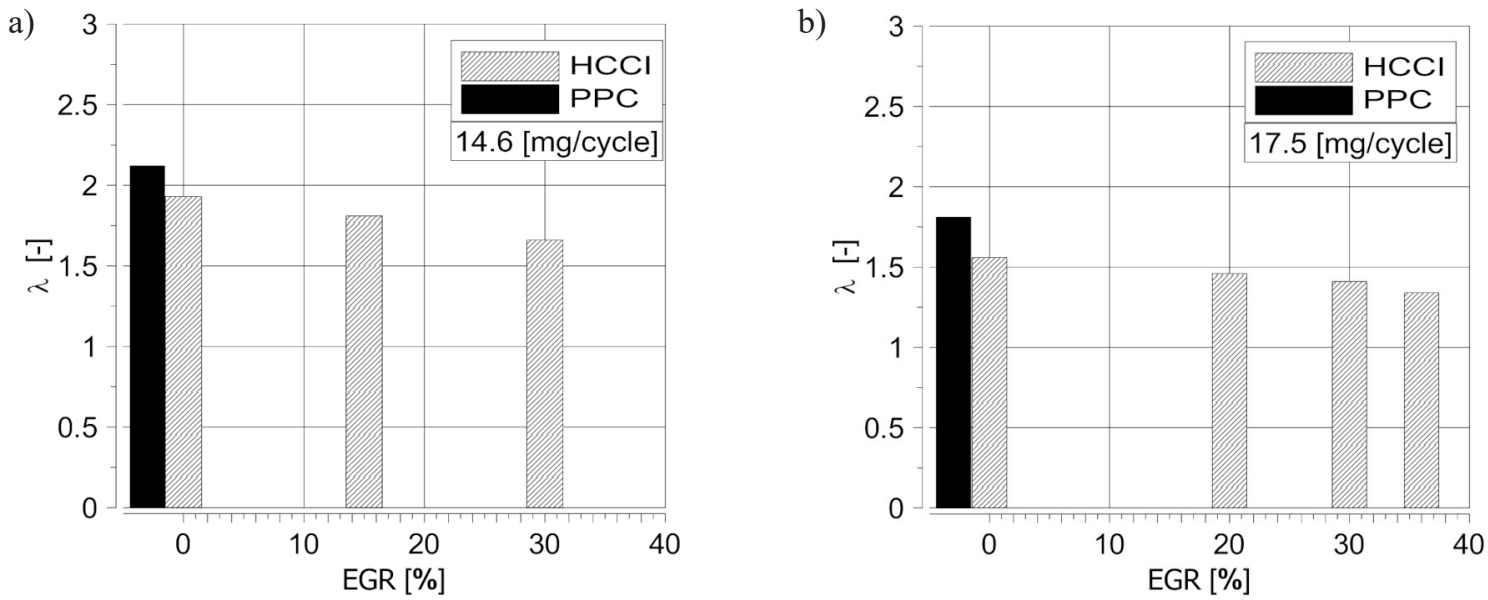

Fig. 3. Air excess ratio $\lambda$ vs. EGR rate for HCCI and PPC process for JP-8 dose $d_{1}=14.6 \mathrm{mg} /$ cycle (a) and for $d_{2}=17.5 \mathrm{mg} /$ cycle (b)

of combustion processes, 100 cycles of in-cylinder pressure for each tested point were measured, and the parameters which describe the combustion process were calculated [6]. Additionally, exhaust gas analysis was done for all tested engine points. All measurements were performed for an engine speed $n=1200 \mathrm{rpm}$. The experiment conditions are described in Table 3.

\section{RESULTS AND DISCUSSION}

The experiment enabled to test the combustion process of a JP-8/air homogeneous mixtures. The previously chosen injection parameters gave us the possibility of combustion at the lower limit of flammability and close to the knock limit. The combustion of a JP-8/air homogeneous mixture was compared to Partially Premixed Combustion (PPC) without dilution. In [12] the lower flammability limit, experimentally determined for this type of kerosene-based aviation fuel is given. It is $\mathrm{F} / \mathrm{A}=0.037$ (air access ratio $\lambda=1.83$ ) for 400 $\mathrm{K}$. The first tested amount of fuel dose $\left(d_{1}=14.6\right.$ $\mathrm{mg}$ /cycle) gave the homogeneous mixture composition at the lower flammability limit (Fig. 3). The HCCI engine operation gave us characteristic cylinder pressure diagrams (Fig. 4a) with a high cylinder pressure rise rate (Fig. 4b). The cylinder pressure rise rate was limited by EGR. The maximum cylinder pressure was relatively low. For an undiluted homogeneous mixture it was 5.2 $\mathrm{MPa}$ (for the first dose $d_{1}=14.6 \mathrm{mg} /$ cycle) and $5.8 \mathrm{MPa}$ (for the second dose $d_{2}=17.4 \mathrm{mg}$ / cycle), but in the second case, the rate of cylinder pressure rise exceed the knock limit and caused a visible single pressure diagram deformation (Fig. 5). Two-stage ignition with separate regions with a small heat release in the low-temperature regime and the main heat release in the high-temperature regime were observed (Fig. 6). The first stage of the HCCI process was visible for all examined homogeneous mixtures, but for an undiluted mixture, it could be seen clearly. The second stage of the HCCI process showed a sudden, characteristic heat release in a short period of time and a corresponding, abrupt pressure rise ,whereas the PPC heat release diagram showed a characteristic domination of the premixed combustion phase. For the set of multi-pulse injections, EGR allowed controlling the phase and the rate of the heat release. It made the heat release process longer and reduced the maximum cylinder pressure. The higher share of EGR gave a possibility to raise the amount of fuel injected to the cylinder per one cycle without excessive growth of the maximum cylinder pressure and to avoid the knock. The low CR caused the low ambient cylinder temperature during the compression stroke, especially during injections, which contributed to a prolonged self-ignition of the homogeneous mixture. At the moment of injection, the ambient temperature in the cylinder was lower than the end-boiling temperature of the heavy fractions of the fuel. It was about $400 \mathrm{~K}$ at $80 \mathrm{deg}$ BTDC, 460 $\mathrm{K}$ at $60 \mathrm{deg} \mathrm{BTDC}$ and $490 \mathrm{~K}$ at $50 \mathrm{deg}$ BTDC. The first stage of the combustion started when the ambient cylinder temperature was about $560 \mathrm{~K}$ for both tested fuel doses. It took nearly $40 \mathrm{CA}$ deg to initiate the low temperature heat release 
(LTHR) when ambient cylinder temperature was about $570 \mathrm{~K}$ (Fig. 7). LTHR raised the charge temperature in the cylinder up to $620 \mathrm{~K}$, but it was still a low value in comparison to that reported in the literature for less reactive fuels than JP-8. The engine load was confined by the rate of cylinder pressure rise and the knock. Indicated Mean Effective Pressure (IMEP) for the HCCI engine operation was close to $0.5 \mathrm{MPa}$, which is reported as the maximum achieved in a naturally aspirated HCCI engine using well mixed fuelair mixture [18]. For the smaller fuel dose $\left(d_{1}\right.$

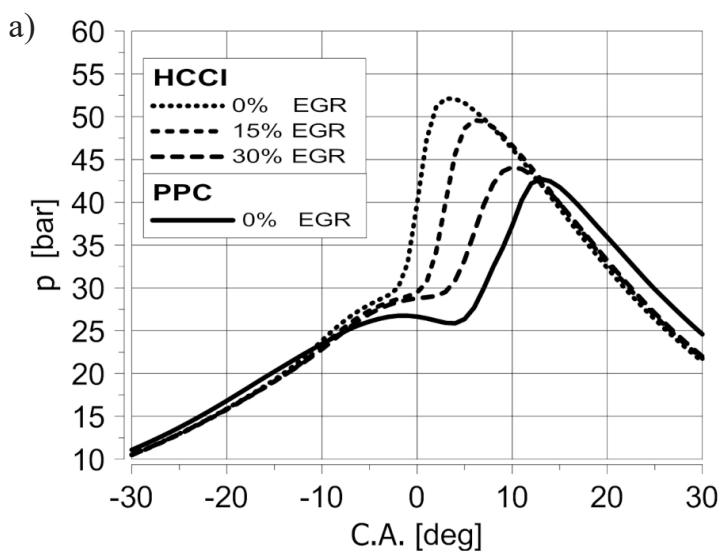

b)
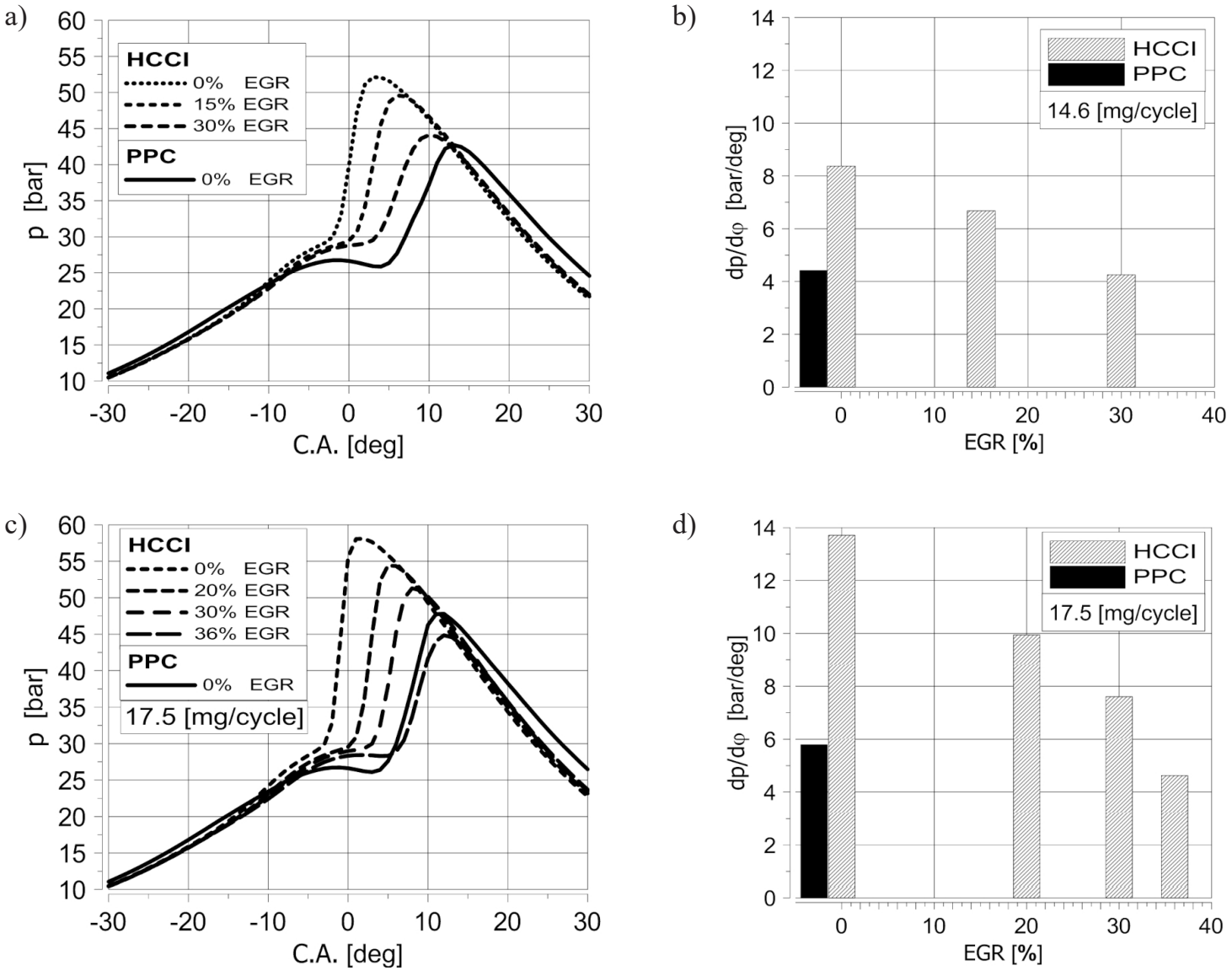

d)

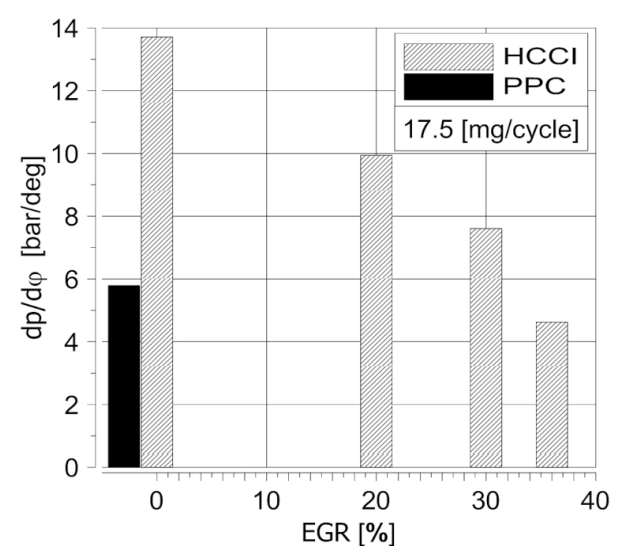

Fig. 4. Cylinder pressure (a), and cylinder pressure rise rate (b) for JP-8 dose $d_{1}=14.6 \mathrm{mg} / \mathrm{cycle}$ and for $d_{2}=17.5 \mathrm{mg} / \mathrm{cycle}$
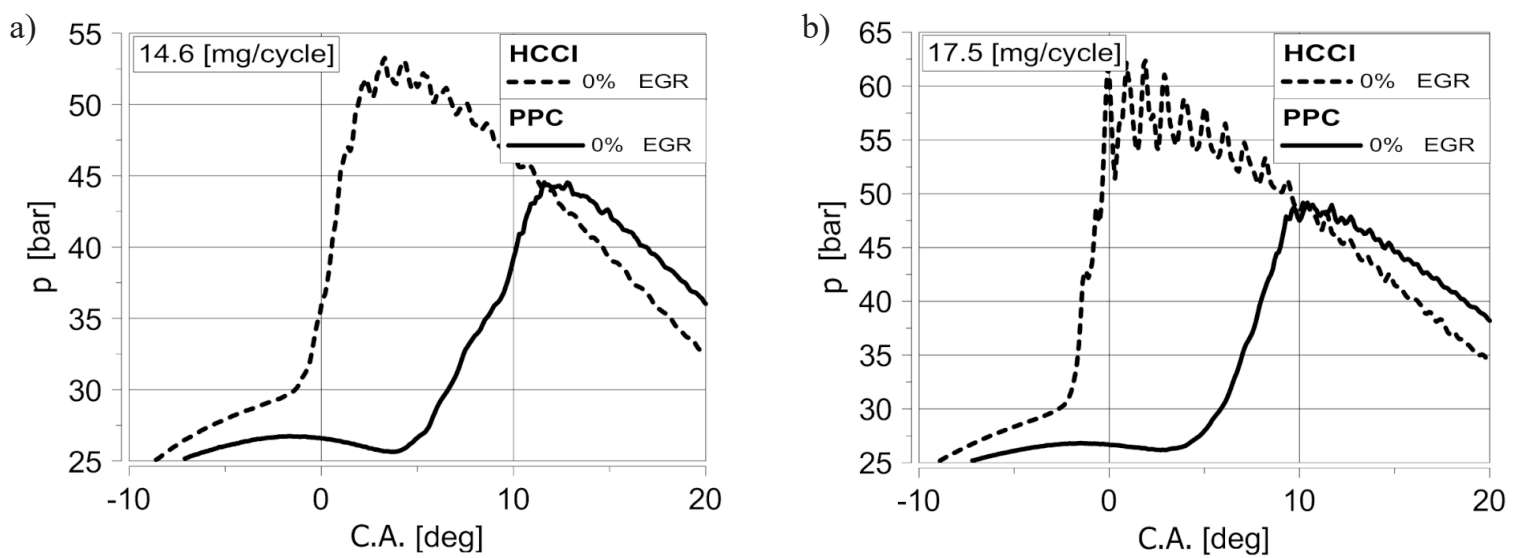

Fig. 5. Cylinder pressure diagrams from a single cycle /fragment/ for JP-8 dose $d_{1}=14.6 \mathrm{mg} /$ cycle (a) and for $d_{2}=17.5 \mathrm{mg} / \mathrm{cycle}$ (b) 
$=14.6 \mathrm{mg} /$ cycle) on the lean operation limit, it was 0.41-0.42 MPa (Fig. 8a). For the higher fuel dose $\left(d_{2}=17.5 \mathrm{mg} /\right.$ cycle $)$ and the richer homogeneous mixtures, IMEP reached 0.46-0.48 MPa, but for this engine operation, a tangible knock appeared (Fig. 8c). For the HCCI engine operation, a local inhomogeneity of the mixture composition is possible, which could contribute to the cycle by cycle variation of the combustion process. For the experimental data, the Coefficient of Variation of Indicated Mean Effective Pressure $\left(\mathrm{CV}_{\text {IMEP }}\right)$ was calculated $(\mathrm{CV}[\%]=$ standard a)
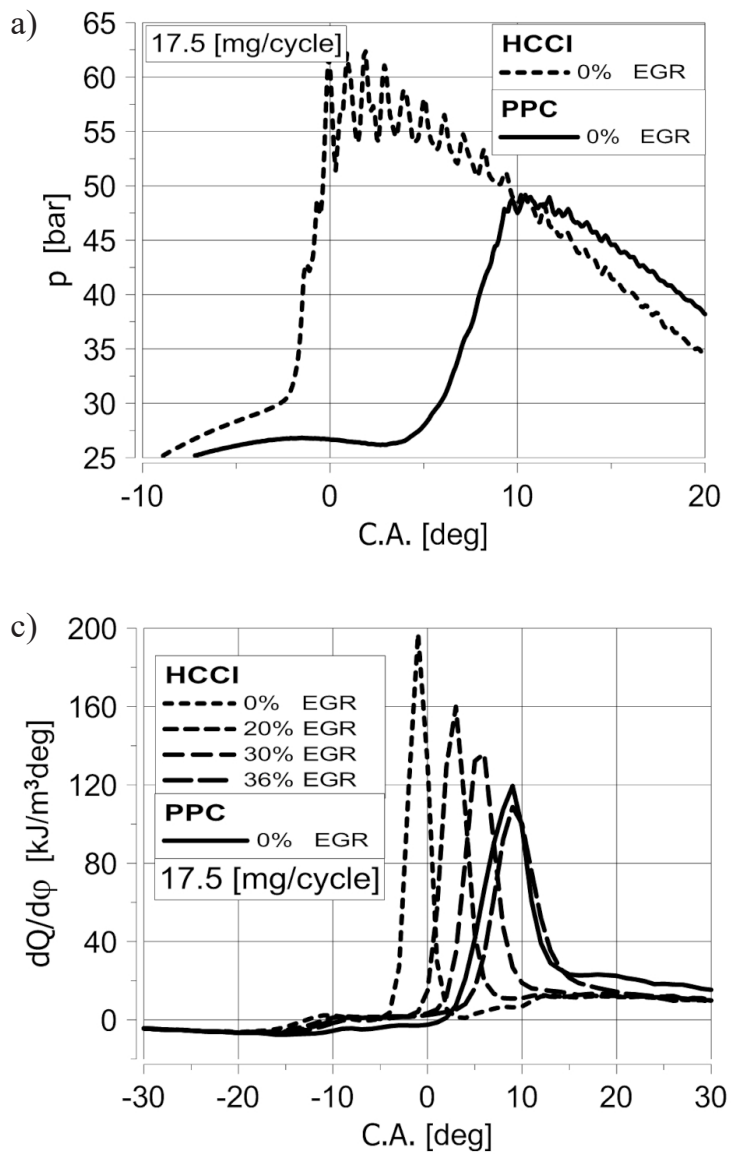

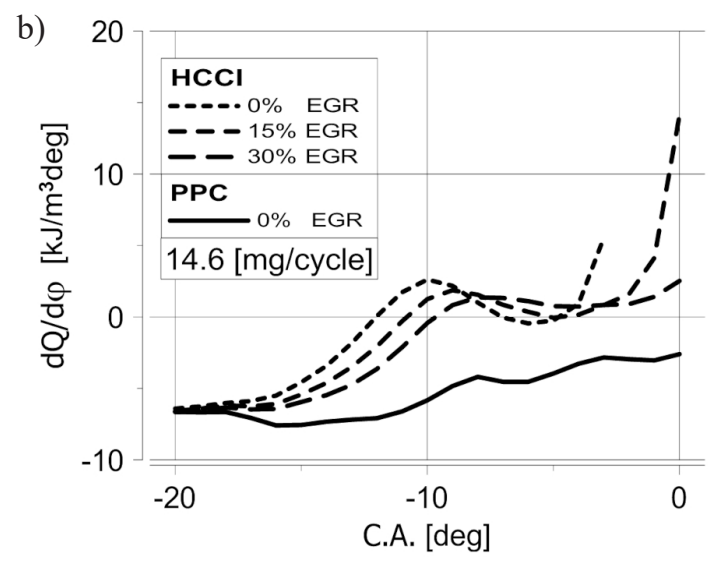

d)

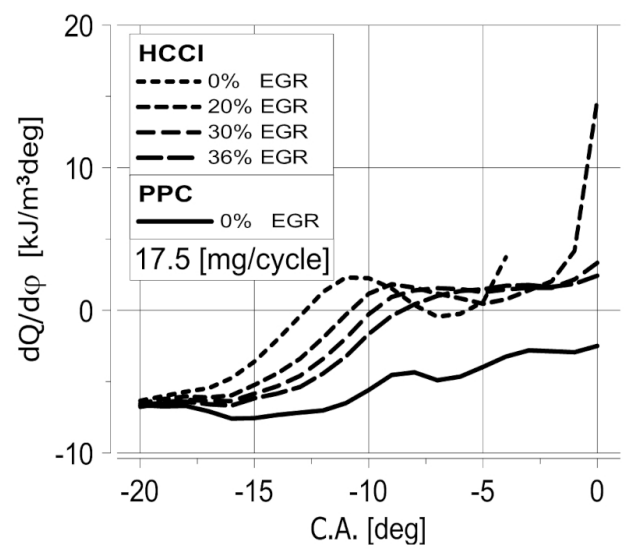

Fig. 6. Heat release rate (a) and its low temperature part (b) for JP-8 dose $d_{1}=14.6 \mathrm{mg} /$ cycle and for $d_{2}=17.5 \mathrm{mg} /$ cycle $(\mathrm{c}),(\mathrm{d})$
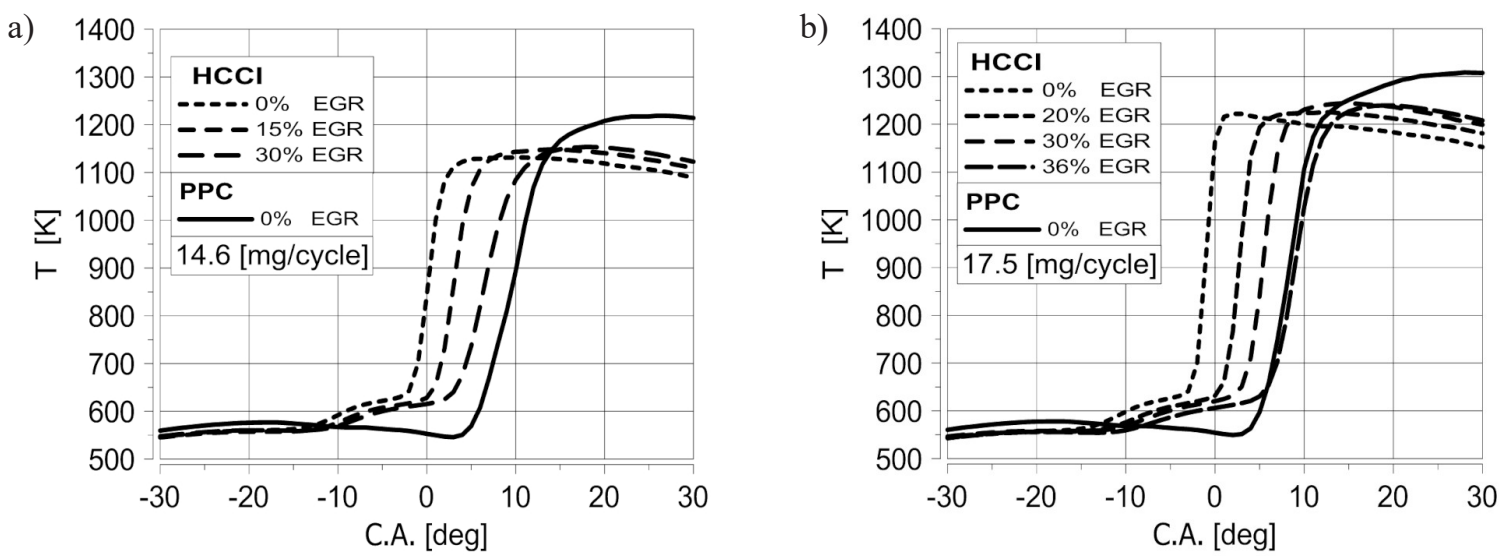

Fig. 7. Ambient cylinder temperature for JP-8 dose $d_{1}=14.6 \mathrm{mg} / \mathrm{cycle}$ (a) and for $d_{2}=17.5 \mathrm{mg} /$ cycle (b) 
deviation of dataset/mean of a dataset). $\mathrm{CV}_{\text {IMEP }}$ is typically used to define the lower engine operating range with a limiting value of $3.5 \%$ [18]. The values obtained in the experiment are lower than the literature limit (Fig. 8b, 8d). It was noted that the higher EGR rate made the HCCI process less repetitive. For the smaller fuel dose and the lower EGR rates for the $\mathrm{HCCI}$ combustion, $\mathrm{CV}_{\text {IMEP }}$ was lower than for PPC. For the greater fuel dose, it was nearly on the same level only for the lower EGR rate. For the HCCI engine operation, only the $\mathrm{NO}_{\mathrm{x}}$ emission was much lower than for the tested Partially Premixed Compression Ignition (PPCI) engine operation. If the EGR rate was high enough, the $\mathrm{NO}_{\mathrm{x}}$ emission was low (Fig. 9a, 9c). The Particulate Matter (PM) emission for the HCCI engine operation was higher than for the PPCI operation, although PPC was realised without EGR (Fig. 9b, 9d). However, generally, it was still a low level of emission. The Total Hydrocarbons (THC) and CO emissions for the HCCI engine operation were influenced by the low ambient temperature in the cylinder, especially during

a)

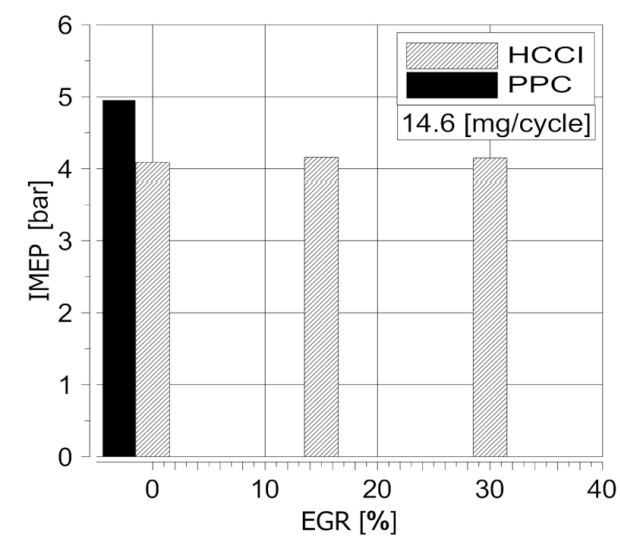

c)

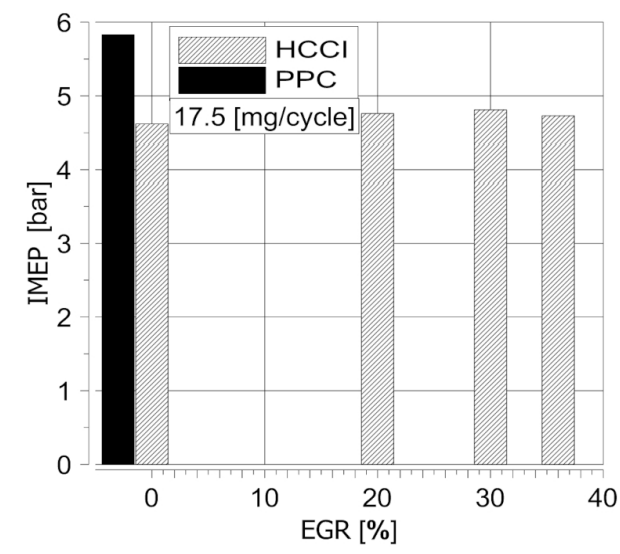

the first stage of the combustion. Therefore, the $\mathrm{CO}$ as well as THC emissions for homogeneous mixtures combustion, remained on a very high level (Fig. 10) which influenced IMEP and the engine thermal efficiency $\eta_{\text {th }}$ (Fig. 11). Generally, a higher intake temperature advances combustion. It largely reduces the engine thermal efficiency, because self-ignition is advanced, which causes a significant negative work on the piston. Because the cylinder temperature during the compression was relatively low, it was possible to realise the HCCI process without EGR and receiving IMEP higher than 4 bar.

\section{CONCLUSIONS}

The results of the experiment show that it is possible to realise a LTC process for the JP-8 fuel in a CI engine equipped with a common rail system with low CR (12:1). The HCCI combustion was realised efficiently without EGR. The combustion of a JP-8 homogeneous mixture can

b)

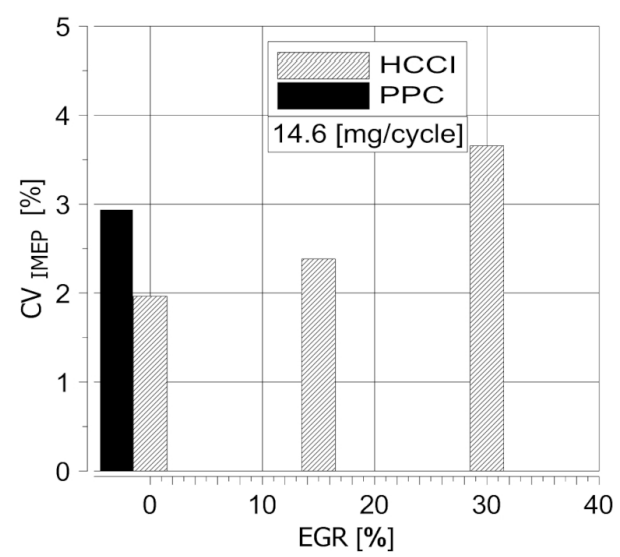

d)

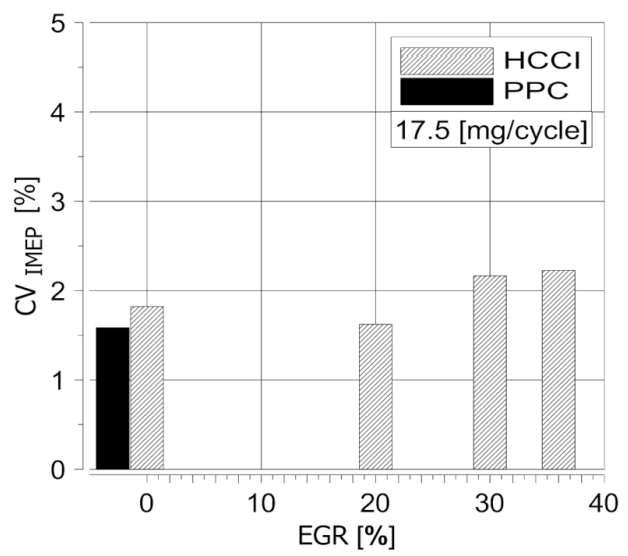

Fig. 8. Indicated Mean Effective Pressure (a) and Coefficient of Variation of IMEP (b) vs. EGR rate for JP- 8 dose $d_{1}=14.6 \mathrm{mg} /$ cycle and $d_{2}=17.5 \mathrm{mg} /$ cycle (c),(d) 
a)

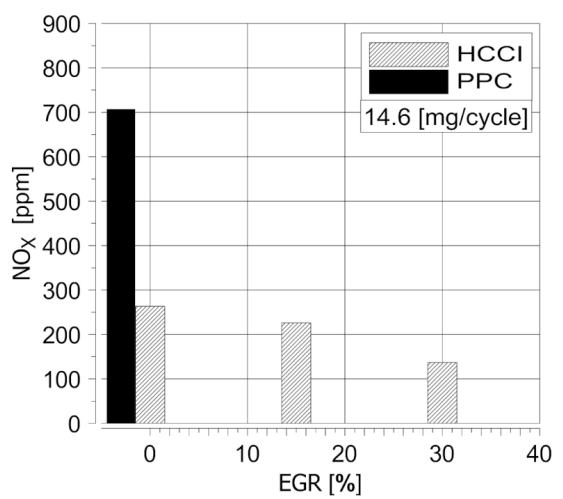

c)

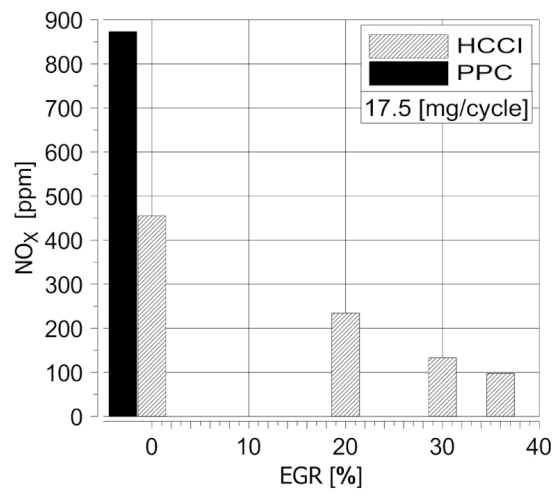

b)

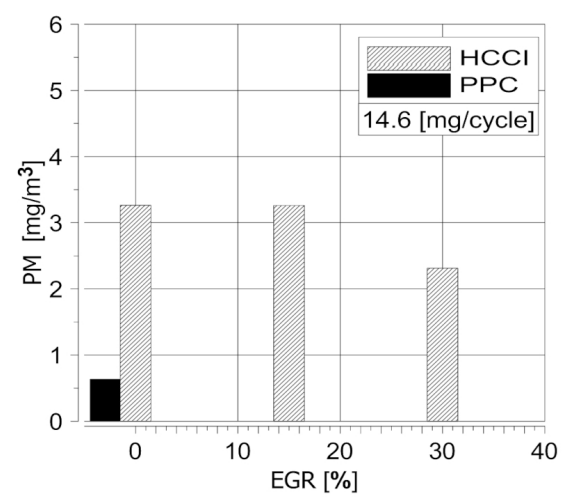

d)

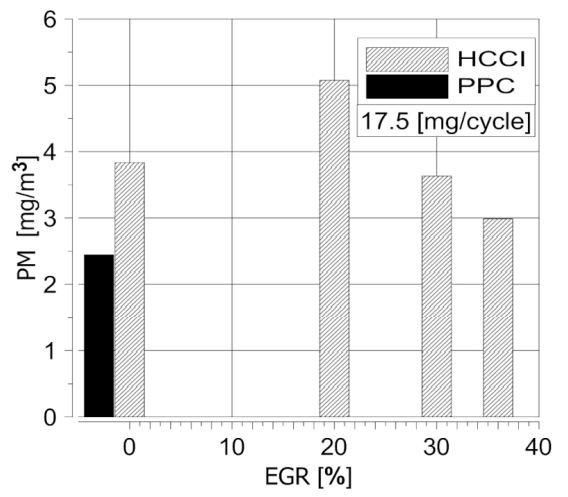

Fig. 9. $\mathrm{NO}_{\mathrm{x}}$ (a) and PM (b) emissions vs. EGR rate for JP-8 dose $d_{1}$ $=14.6 \mathrm{mg} /$ cycle and $d_{2}=17.5 \mathrm{mg} /$ cycle $(\mathrm{c}),(\mathrm{d})$

a)

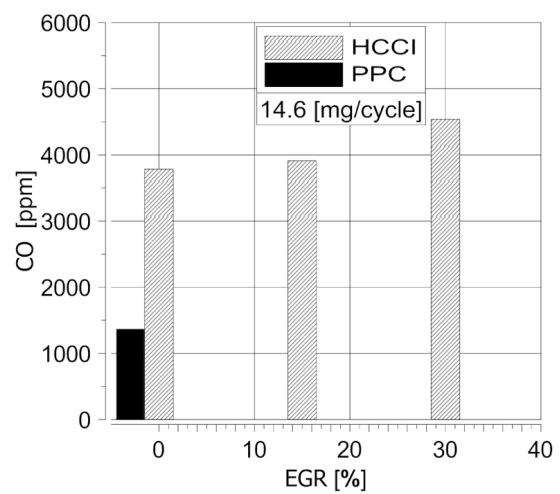

c)

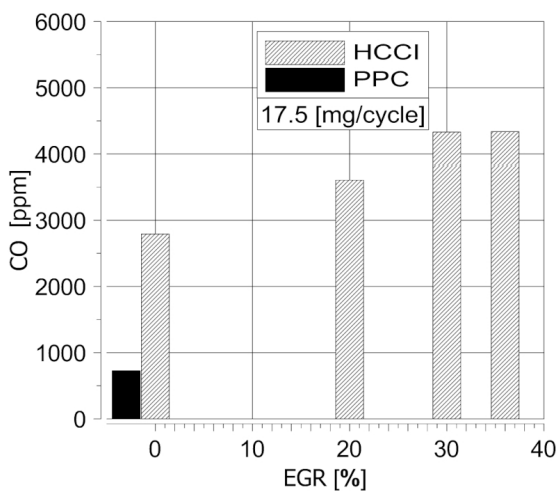

b)

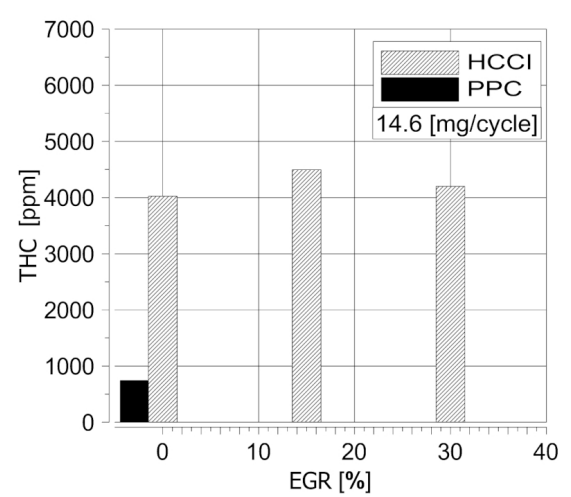

d)

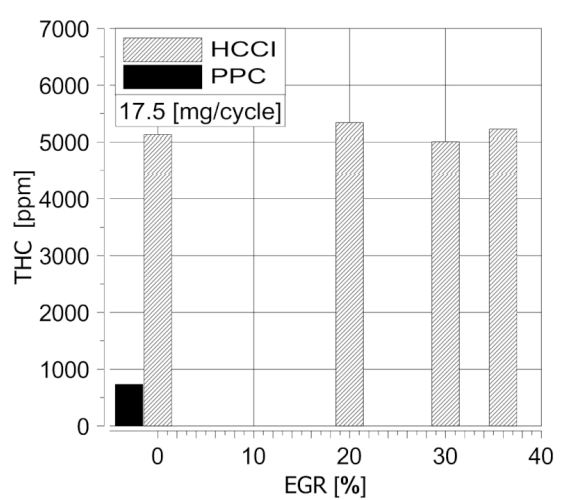

Fig. 10. CO and THC emissions vs. EGR rate for JP-8 dose $d_{1}=14.6$ $\mathrm{mg} /$ cycle (a),(b) and $d_{2}=17.5 \mathrm{mg} /$ cycle (c),(d) 
a)

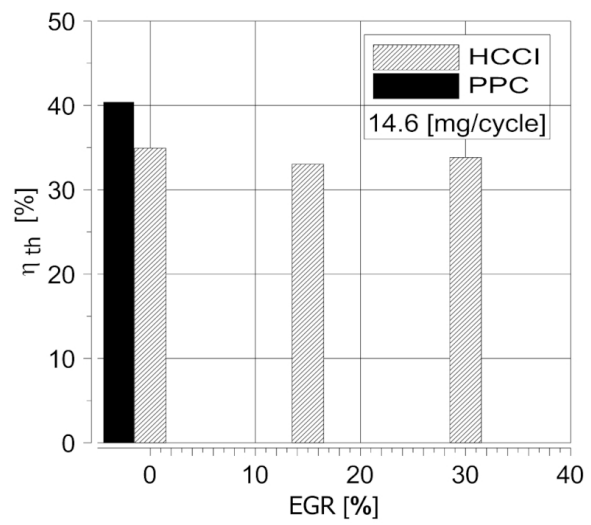

b)

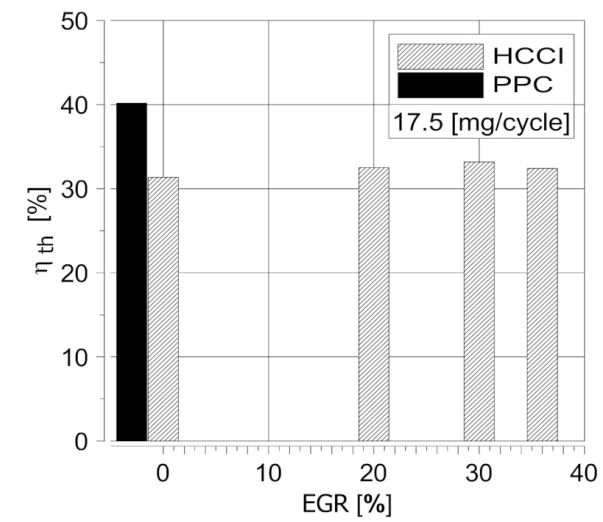

Fig. 11. Engine thermal efficiency $\left(\eta_{t h}\right)$ vs. EGR rate for LTC and PPC process for JP-8 dose $d_{1}=14.6 \mathrm{mg} /$ cycle (a), and $d_{2}=17.5 \mathrm{mg} /$ cycle (b)

be controlled and the low ambient cylinder temperature, especially for the compression stroke, increases the possibilities of the combustion control creating a space for a high pressure rise. The effective HCCI engine operation was possible for the lean air/fuel mixture composition close to the flammability limit (fuel dose $d_{1}$ ). For the richer mixture obtained for the greater dose of the fuel (fuel dose $d_{2}$ ), the diesel knock was appearing and limiting engine operation. For the HCCI engine operation, the $\mathrm{NO}_{\mathrm{x}}$ emission was much lower than for PPC and depended on EGR rate. The Particulate Matter (PM) emission for the HCCI engine operation was higher than for the PPC mode, although PPC was realised without EGR. Despite a relatively high IMEP (close to $0.5 \mathrm{MPa}$ ), high THC and CO emissions were observed. It is a task for the future research. The nozzle used in the experiment was not optimised for JP-8. The cone angle of the nozzle used in the test was $162 \mathrm{deg}$. It was possible that fuel droplets reached the cylinder wall and created an additional emission of THC and a drop of engine thermal efficiency $\eta_{\text {th }}$. PPC of the JP-8 fuel also makes a very interesting research area. The $\mathrm{CR}$ applied in the experiment was too low for this process, but the test showed that even for this value of CR it is possible to get the engine thermal efficiency higher than $40 \%$. For a higher CR, high EGR shares could be tested and optimised.

\section{REFERENCES}

1. Bendu H., Murugan S. Homogeneous charge compression ignition (HCCI) combustion: Mixture preparation and control strategies in diesel engines. Renewable and Sustainable Energy Reviews, 38, 2014, 732-746.
2. Charalambides A.G. Homogenous Charge Compression Ignition (HCCI) Engines. Advances in Internal Combustion Engines and Fuel Technologies edited by Hoon Kiat Ng, Chapter 4, 2013.

3. Fernandes G., Fuschetto J., Filipi Z., Assanis D., McKee H. Impact of Military JP-8 Fuel on Heavy Duty Diesel Engine Performance and Emissions. Proceedings of the Institution of Mechanical Engineers, Part D: Journal of Automobile Engineering 2007, 221, 957-970.

4. Gan S., Ng H.K., Pang K.M. Homogeneous Charge Compression Ignition (HCCI) combustion: Implementation and effects on pollutants in direct injection diesel engines. Appled Energy, 88, 2011, 559-567.

5. Handbook of aviation fuel properties. CRC Report No. 635, Third Edition, 2004.

6. Heywood J.B. Internal combustion engine fundamentals. International editions. Singapore, McGraw-Hill, 1988.

7. Jinwoo L., Choongsik B. Application of JP-8 in a heavy duty diesel engine. Fuel, 2011, 90, 1762-1770.

8. Jungyeon L., Sanghyun C., Hoimyung C., Kyoungdoug M. Emission reduction potential in a lightduty diesel engine fueled by JP-8, Applied Energy, 2015, 89, 92-99.

9. Karczewski M., Szczech L. Influence of the F-34 unified battlefield fuel with biocomponents on usable parameters of the IC engine. Eksploatacja i Niezawodność - Maintenance and Reliability, 18, 2016, 358-366.

10. Kim M.Y., Lee C.S. Effect of a narrow fuel spray angle and a dual injection configuration on the improvement of exhaust emissions in a HCCI diesel engine. Fuel, 86(17-18), 2007, 2871-80.

11. Lee J., Bae C. Application of JP-8 in a heavy duty diesel engine. Fuel, 90(5), 2011, 1762-1770.

12. Li A. Flammability limits of alternative aviation fuels. Open Access Theses. 869, 2016. 
13. Maurya R.K. Characteristics and Control of Low Temperature Combustion Engines Employing Gasoline, Ethanol and Methanol, Springer, 2018.

14. Maurya R.K., Agarwal A.K. Experimental study of combustion and emission characteristics of ethanol fueled port injected homogeneous charge compression ignition (HCCI) combustion engine. Applied Energy, 88, 2011, 1169-1180.

15. NATO Logistics Handbook 1997.

16. Peng Z., Zhao H., Ma T., Ladommatos N. Characteristics of homogeneous charge compression ignition (HCCI) combustion and emissions of n-heptane. Combustion Science and Technology, 2005.

17. Pickett L., Hoogterp L. Fundamental Spray and Combustion Measurements of JP-8 at Diesel Con- ditions. SAE International Journal of Commercial Vehicles 1(1), 2009, 108-118.

18. Richter M., Engström J., Franke A., Aldén M., Hultqvist A., Johansson B. The Influence of Charge Inhomogeneity on the HCCI Combustion Process", SAE Paper 2000-01-2868, 2000.

19. Saxena S., Bedoya I.D. Fundamental phenomena affecting low temperature combustion and HCCI engines, high load limits and strategies for extending these limits. Progress in Energy Combustion Science, 39(5), 2013, 457-488.

20. Zhao F., Asmus T.W., Assanis D.N., Dec J.E., Eng J.A., Najt P.M. Homogeneous charge compression ignition (HCCI) engines: key research and development issues. SAE PT-94, 2003. 